\title{
Applications of X-Ray Computed Tomography for Examining Soil Structure: A Review
}

\author{
Anca-Elena CALISTRU ${ }^{1}$, Gerard JITĂREANU ${ }^{1}$ \\ ${ }^{1}$ Faculty of Agriculture, University of Agricultural Sciences and Veterinary Medicine of Iasi, M. \\ Sadoveanu Alley No. 3, zip code 700490, Romania; \\ * corresponding author: ancaelenacalistru@gmail.com
}

Bulletin USAMV series Agriculture 72(1)/2015

Print ISSN 1843-5246; Electronic ISSN 1843-5386

DOI 10.15835/buasvmcn-agr: 11145

\begin{abstract}
In this paper we present a review of the application of X-ray computed tomography in soil science, a modern technique for structural analysis. The quantification of internal soil structure is the key in understanding the processes that lead to its development. The current analytical and traditional methods for exploring soil structure do not fully cover the needs of the researchers, in order to characterize the soil system and its properties. In the last decades, X-ray computed tomography has provided a non-destructive means in order to observe and quantify soils in 3D. It has been used in researches regarding the spatial distribution of soil pores, bulk density, macropore network structure, layer detection, permeability, calculated fractal properties, solute breakthrough, root system development etc. Compared to other analysis methods, the short time requiered for a CT scan (within the order of minutes) and the accuracy of the data provided, recommend this technique for the characterization of soil systems.
\end{abstract}

Keywords: physical properties, soil structure, X-ray CT.

\section{INTRODUCTION}

Computed tomography (CT) is an efficient technique which is nowadays used in many soil studies. At first, it was used in medicine, starting with the late 1960s, when Cormack and Hounsfield built the first computed tomography scanner, for which they received in 1979 the Nobel Prize for Medicine (Losano et al., 1999). The last decades bought a development of the range of areas where it can be applied. In 1974, Fourie used for the first time the CT in his researches of paleontology, and after that Conroy and Vannier (1984) and Houbitz et al. (1988) also used it with great success. In sedimentology, it was used by researchers for the analysis of sedimentary structures (Kenter, 1989; Peyton et al., 1992; Zeng et al., 1996). It was also used for the study of rock porosity, material density and fractures (Jacobs et al., 1995; Keller, 1997; Jacobs et al., 1997; Klobes et al., 1997). The researches regarding the use of X-ray CT in soil science focused on the spatial distribution of soil properties (Young et al., 2001; Rogasik et al., 2003; Nunan et al., 2006), layer detection (Lipiec and Hatano, 2003), pore network structures (Al-Raoush and Willson, 2005), permeability (Ketcham and Carlson, 2001; Mooney, 2002), solute breakthrough (Clausnitzer and Hopmans, 2000), seedbed preparation (Atkinson et al., 2007) and calculated fractal properties (Gantzer and Anderson, 2002; De Gryze et al., 2006; Papadopoulos et al., 2008).

The aim of this study is to present a review of the application of X-ray CT in soil science, as a modern technique for structural analysis.

\section{Overview of the X-ray CT technique}

$\mathrm{X}$-ray CT is a non-invasive technique that can be used to visualize the interior of objects in 2D and 3D based on the principle of attenuation of an electromagnetic wave (Helliwell et al., 2013). A typical scan involves the collection of a series of radiograph images of a sample acquired at 
incremental angular positions, normally over $360^{\circ}$. Generally, X-ray CT scanners consist of three common parts: an X-ray source, a sample manipulation stage and a detector. X-rays emitted from the source pass through the sample and are progressively attenuated by absorption and scattering as the object itself becomes a secondary source of X-rays and electrons through atomic interactions (Mooney et al., 2012). The characteristic of a material to either absorb or scatter a photon is known as attenuation coefficient. Attenuation coefficients are related to the density of the absorbing material, electron density of the voxel of interest and incident X-ray energy, but are predominantly controlled by four dominant processes: photoelectric absorption, Rayleigh scattering, Compton scattering and pair production (Helliwell et al., 2013). However, it should be noted that pair production occurs at X-ray energies (1.022 MeV) far greater than conventional X-ray CT systems. Integration of the linear X-ray attenuation coefficient values from the multitude of radiographic images form the basis of tomographic reconstruction (Taina et al., 2008). It is based frequently on mathematical filtered back-projection algorithms, through which crosssectional 2D image slices are generated from radiograph projection images (Wildenschild et al., 2002; Stock, 2008). Each non-invasive tomographic 'slice' consists of discrete units known as voxels (3D pixels), the size of which reflects the spatial resolution of the scan.

\section{Applications in soil science}

Soil constituents and organic matter

Sleutel et al. (2008) used scan data from four X-ray CT systems, which used different X-ray sources of various energy spectra, detectors of differing sensitivity and beam filters of different thicknesses in order to threshold images of a sandorganic matter mix.

X-ray CT has also been used by Quinton et al. (2009) and Kettridge and Binley (2011) in order to study highly organic soils such as peats.

Elyeznasni et al. (2012) recovered part of the discontinuous pattern of organic matter fragments in the macro-porosity of the soil after detecting coarse-sized organic matter concentrations in $\mathrm{X}$-ray CT images.

Mineral classification by X-ray CT has been widely made in petrological studies done by Van
Geet et al. (2000), Ketcham (2005) and Stock (2008).

Twenty years ago, in 1994, the first who applied medical X-ray CT in order to analyze offshore sediment cores non-destructively were Orsi et al. (1994), and so they were able to successfully characterize the sediment morphology (Orsi and Anderson, 1995).

Using a medical system for spatially mapping the 3D distribution of quartz, feldspar and micas based on their radiological densities, Geraud et al. (2003) compared the radiological densities of the main mineral phases with measured values on macroscopic crystals, confirming mineral presence in the sample.

In the year 2000, Kalukin et al. successfully used principal components analysis (PCA) of images from X-ray scan in order to enhance the contrast between individual minerals more clearly than was possible in single-energy X-ray CT scans.

Feeney et al. (2006) and Wang et al. (2012) used voxel with sizes $<15 \mu \mathrm{m}$ allowing interpretations of fractions finer than sand.

\section{Soil compaction and porosity}

Various studies have used X-ray CT to quantify properties of macropore network morphology, including pore diameter (Anderson et al., 1992; Zeng et al., 1996), crack formation (Peth et al., 2010), pore network structure (Baveye et al., 2002; Aravena et al., 2011) and pore circularity (Gantzer and Anderson, 2002).

In order to demonstrate a clear advantage of X-ray CT over other invasive techniques, AlRaoush and Willson (2005) used skeletonization algorithms (thinning operations, which systematically remove voxels from an object until a minimal but topologically identical structure is produced) to extract pore-bodies, pore-throats and size distributions in physically realistic pore network structures, that enabled the discrimination of active and inactive pores and the characterization of redundant pore throats.

In their researches, Delerue et al. (2003) successfully developed a pore network directly from soil images by integrating pore size and connectivity parameters, which enabled calculation of the equivalent hydraulic conductivity from a 3D image of any porous soil.

Elliot and Heck (2007) compared the optical and the CT method for the determination of 
void space, using four thin section samples. After registering the two imagery types, they extracted for analysis an identical region of optical and CT imagery. The results showed that the optical method was proficient in identifying continuous and linear void features, whereas CT readily identified a greater number of voids with higher circularity. The data also suggested that the CT method identified a greater degree of void space in thin section than was evident to the optical classification, fact that prove that CT is a great complementary technique to the soil micromorphology tool set.

Sander et al. (2008) used the X-ray CT to visualize the size and connectivity of structural pores including arrangement of aggregates and to quantify the vertical bulk density distribution in the upper soil horizons affected by cultivation in paddy fields. Undisturbed soil columns of $10 \mathrm{~cm}$ diameter (5-42 $\mathrm{cm}$ and 0-38 $\mathrm{cm}$ depth) including the plough pan transition down to the subsoil were scanned using a medical X-ray CT. Vertical bulk density profiles were calculated from Hounsfield Units (HU) and gravimetric water contents measured in $10 \mathrm{~mm}$ and particle densities in 20 to $50 \mathrm{~mm}$ vertical intervals. Secondary pores were separated using 2 HU-threshold values and described by 3D plots of 'air-filled' and 'lowdensity' regions; the matrix structures were analyzed by 2D CT-images.

In their studies, Rogasik et al. (2003) assessed macropore length, size and connectivity of pores under different agricultural practices at the spatial scale of $0.25 \times 0.25 \times 1 \mathrm{~mm}$.

The effect of soil compaction on 3D macropore geometry was characterized by Kim et al. (2010) in undisturbed field cores. They were able to reveal the total macro- and mesopore numbers associated with an increase in surface compaction, by using X-ray CT in addition to recording decreases in overall porosity and bulk density. They were also able to assess the degree of correlation between additional CT-measured pore characteristics, including largest pore circularity, fractal dimensions and pore area.

Luo et al. (2010) used the X-ray CT to quantify 3D macropore networks in intact soil columns using an improved approach and to investigate the effects of soil type and land use on soil macropore characteristics. They used samples from two soils with contrasting textures and structures from two land uses (row crop and pasture). Intact soil columns, $102 \mathrm{~mm}$ in diameter and about $350 \mathrm{~mm}$ in length, were taken for each soil type-land use combination. The soil columns were scanned using X-ray computed tomography at a voxel resolution of $0.234 \mathrm{~mm} \times 0.234 \mathrm{~mm} \times$ $2.000 \mathrm{~mm}$. The characteristics of the macropore networks were quantified, including continuous macroporosity change along depth, macropore size distribution, network density, surface area, length density, length distribution, mean hydraulic radius, tortuosity, inclination (angle), and connectivity (path number and node density). The results of the study provide improved evaluation of soil macropore characteristics with important implications for non-equilibrium flow prediction and chemical transport modeling in field soils.

\section{Soil structure modification analysis}

In order to interpret soil structure, there have been used destructive techniques and observations in 2D, including thin sections and electron microscopy (Young et al., 2001). X-ray CT has been used in many studies to describe the spatial nature of soil constituents in undisturbed systems (Perret et al., 2007; Torrance et al., 2008; Elliot et al., 2010; Flavel et al., 2012; Mairhofer et al., 2012; Schmidt et al., 2012; Tracy et al., 2012).

Peth et al. (2010) quantified the effect of hydraulic stress on the dynamic rearrangement of solid particles at a resolution of $38.4 \mu \mathrm{m}$, providing a good example of the potential of X-ray CT as a good means of investigation. They used digital image reconstructions to quantify local structural pore space characteristics and local soil deformation by 3D morphological and correlation analysis of grayscale tomograms. Swelling and shrinkage resulted in a complex heterogeneous soil structure which proved to be very stable when mechanical loads were applied. The mechanism of soil deformation for both structure formation by internal hydraulic stresses and structure degradation by external mechanical stresses were in both cases controlled by pre-existing microstructures. Especially during wetting such structures served as a core for subsequent structure evolution. The results demonstrate the potential of more detailed non-invasive analysis of soil deformation processes which could improve the conceptual understanding of the physical behavior of soil systems. 
Water content, and water and solute transport

The CT method was also used to investigate the water movement in soil, which accounts for the 3D interconnected void space (Perret et al., 2000; Kasteel et al., 2000; Mooney, 2002; Wildenschild et al., 2005).

There have been used tracer solution of iodide (NaI or $\mathrm{KI}$ ) or bromide $\left(\mathrm{CaBr}_{2}\right)$ for the assessment of solute transport in porous media, due to their high contrasting X-ray attenuation of iodine and bromide ions (Clausnitzer and Hopmans, 2000; Anderson et al., 2003).

In order to visualize and quantify the soil macroporosity and water flow pattern, Mooney (2002) used undisturbed samples of various soil textural types that were scanned using a fourth generation Picker PQ6000 whole-body X-ray CTscanner, with no pretreatment of the samples. The $\mathrm{X}$-rays were generated with an exposure factor of $120 \mathrm{kV}$ and $100 \mathrm{~mA}$ using a standard spiral scan routine. Images were collected at c. $0.5 \mathrm{~mm}$ intervals with a slice thickness of c. $0.5 \mathrm{~mm}$. The resolution of the scanners output device was $512 \mathrm{x}$ 512 and the final spatial resolution of each volume unit (voxel) was $0.46 \mathrm{~mm} \times 0.46 \mathrm{~mm} \times 0.46 \mathrm{~mm}$. The results showed that in general, the pore space was characterized by low densities and the mineral material had high densities. The soil porosity was predominantly comprised of horizontally orientated angular cracks and irregular shaped pores.

Baveye et al. (2002) revealed the dependence of macroscopic soil properties such as volumetric water content, bulk density and air content on sampling volume, positioning and shape. They showed that properties in small volumes can exhibit erratic fluctuations in measurements, which can be stabilized as sampling volume increases.

The research conducted by Carminati et al. (2009) shows the appearance of a so-called 'gap' between lupin roots and the soil along with the decrease of the transpiration rate, indicating that the gap was the result, not the cause of water limitation to the plants.

Evaluation of the effect of different soil management systems

Gantzer and Anderson (2002) assessed the impact of different agricultural tillage practices on the mechanical stability of soils and the resulting seedbeds. The study carried out on intact soil samples from conventional chisel-disc plough and no-tillage systems revealed that the chisel-disc system had higher number of macropores and a $94 \%$ and $62 \%$ increase in macropore circularity and perimeter, respectively.

The X-ray CT has been also used by Atkinson et al. (2009) to describe the temporal evolution of a seedbed at the mesoscale, from pre-through to post-cultivation. Their research revealed that the use of disc and rolling treatments can lead to porous seedbeds, which can reduce crop establishment because of poor seed-soil contact.

In a study carried out by Papadopoulos et al. (2009) are compared stable and unstable aggregate fractions from organically and conventionally managed soils in order to evaluate the role of management on aggregate stability and structure.

\section{Future expectations}

Even if the last 25 years, the CT technique has evolved, being used on a wide range of areas, there are still a lot of studies to be done, regarding not only the soil structure, composition and its modifications, but also on the influence of the multiple scanning on the same sample (Tracy et al., 2012; Sun et al., 2012).

Also, is needed an improvement of the sample size, image contrast and resolution. When source energy is too high, the sample becomes transparent to the X-rays, and when is too low, there are insufficient X-rays passing through the object and the results are not conclusive (Wildenschild et al., 2002; Helliwell et al., 2013).

An interesting technique is 'region of interest' scanning, providing high resolution CT images of a region in the interior of an object. It requires high resolution acquisition for the region of interest, combined with a second scan of the same plane for the full width of the object, at low resolution; the second scan is used to provide information about the part of the object that is outside the field of view during acquisition for the high resolution scan (Mees et al., 2003).

It is expected that in the next years, CT will become a routine research tool, used on a higher number of samples, with better results. 
Acknowledgements. This paper was published under the frame of European Social Fund, human Resources Development Operational Programme 2007-2013, project no. POSDRU/159/1.5/ S/132765.

\section{REFERENCES}

1. Anderson SH, Peyton RL, Wigger JW, Gantzer CJ (1992) Influence of aggregate size on solute transport as measured using computed tomography. Geoderma 53:387-398.

2. Anderson SH, Wang H, Peyton RL, Gantzer CJ (2003) Estimation of porosity and hydraulic conductivity from X-ray CT-measured solute breakthrough. Applications of X-ray computed tomography in the geosciences. Geological Society, London, UK. Special Publications 215: 135-149.

3. Al-Raoush RI , Willson CS (2005). Extraction of physically realistic pore network properties from threedimensional synchrotron X-ray microtomography images of unconsolidated porous media systems. Journal of Hydrology 300:44-64.

4. Aravena JE, Berli M, Ghezzehei TA, Tyler SW (2011). Effects of root-induced compaction on rhizosphere hydraulic properties- X-ray microtomography imaging and numerical simulations. Environmental Science and Technology 45:425-431.

5. Atkinson BS, Sparkes DL, Mooney SJ (2009). Effect of seedbed cultivation and soil macrostructure on the establishment of winter wheat (Triticum aestivum). Soil and Tillage Research 103:291-301.

6. Baveye P, Rogasik H, Wendroth O, Onasch I, Crawford JW (2002). Effect of sampling volume on the measurement of soil physical properties:simulation with X-ray tomography data. Measurement Science and Technology 13:775-784.

7. Clausnitzer V, Hopmans JW (2000). Pore-scale measurements of solute breakthrough using microfocus X-ray computed tomography. Water Resources Research 36:2067-2079.

8. Conroy GC, Vannier, MW (1984). Noninvasive threedimensional computer imaging of matrix-filled fossil skulls by high-resolution computed tomography. Science 226:456-458.

9. De Gryze S, Jassogne L, Six J, Bossuyt H, Wevers M, Merckx $\mathrm{R}$ (2006). Pore structure changes during decomposition of fresh residue: X-ray tomography analyses. Geoderma 134: 82-96.

10. Delerue JF, Perrier E, Timmerman A, Swennen R (2003). 3D Soil image characterization applied to hydraulic properties computation. In: Applications of X-ray Computed Tomography in the Geosciences (eds F. Mees, R. Swennen, M. Van Geet and P. Jacobs). Geological Society Special Publication, London :167-176.

11. Elliot TR, Reynolds WD, Heck RJ (2010). Use of existing pore models and X-ray computed tomography to predict saturated soil hydraulic conductivity. Geoderma 156:133142.
12. Elliot TR, Heck RJ (2007). A comparison of optical and $\mathrm{X}$-ray CT technique for void analysis in soil thin section. Geoderma 141:60-70.

13. Elyeznasni N, Sellami F, Pot V, Benoit P, VieubléGonod L, Young I, Peth S (2012). Exploration of soil micromorphology to identify coarse-sized OM assemblages in X-ray CT images of undisturbed cultivated soil cores. Geoderma 179:38-45.

14. Feeney DS, Crawford JW, Daniell T, Hallett PD, Nunan N, Ritz K (2006). Three-dimensional microorganization of the soil-rootmicrobe system. Microbial Ecology 52:151158.

15. Flavel RJ, Guppy CN, Tighe M, Watt M, McNeill A, Young IM (2012). Non-destructive quantification of cereal roots in soil using high-resolution X-ray tomography. Journal of Experimental Botany 63:2503-2511.

16. Fourie S (1974). The cranial morphologhy of Thrinaxondon liohinus Seeley. Annals of the South African Museum 65:337-400.

17. Gantzer CJ, Anderson SH (2002). Computed tomographic measurement of macroporosity in chisel-disk and notillage seedbed. Soil and Tillage Research 64: 101-111.

18. Geraud Y, Surma F, Mazerolle F (2003). Porosity and fluid flow characterization of granite by capillary wetting using X-ray computed tomography. Geological Society, London, Special Publications 215:95-105.

19. Haubitz B, Prokop M, Dohring W, Ostrom JH, Wellnhofer P (1988). Computed tomography of Archaeopteryx. Paleobiology 14(2):206-213.

20. Helliwell JR, Sturrock CJ, Grayling KM, Tracy SR, Flavel RJ, Young IM (2013). Applications of X-ray computed tomography for examining biophysical interactions and structural development in soil systems: a review. European Journal of Soil Science 64(3):279-297.

21. Jacobs P, Sevens E, Kunnen M (1995). Principles of computerized X-ray tomography and applications to building materials. Science of the Total Environment 167:161-170.

22. Jacobs P, Sevens E, Vossaert P, Kunnen M (1997). Non-destructive monitoring of interactive physical and biological deterioration of building stones by computerized X-ray tomography. In: Marinos, Koukis, Tsiambaos and Stournaras (Eds.). Engineering Geology and Environment, Balkema, Rotterdam: 3163-3168.

23. Kalukin AR, Van Geet M, Swennen R (2000). Principal components analysis of multienergy X-ray computed tomography of mineral samples. IEEE Transactions on Nuclear Science 47:1729-1736.

24. Kasteel R, Vogel H-J, Roth K (2000). From local hydraulic properties to effective transport in soil. European Journal of Soil Science 51:81-91.

25. Keller AA (1997). High resolution CAT imaging of fractures in consolidated materials. International Journal of Rock Mechanics and Mining Sciences 34(3-4):358.

26. Kenter JAM (1989). Applications of computerized tomography in sedimentology. Marine Geotechnology 8:201-211. 
27. Ketcham RA (2005). Three-dimensional grain fabric measurements using high-resolution X-ray computed tomography. Journal of Structural Geology 27:1217-1228.

28. Kettridge N, Binley A (2011). Characterization of peat structure using X-ray computed tomography and its control on the ebullition of biogenic gas bubbles. Journal of Geophysical Research 116:G01024.

29. Kim H, Anderson SH, Motavalli PP, Gantzer CJ (2010). Compaction effects on soil macropore geometry and related parameters for an arable field. Geoderma 160:244-251.

30. Klobes P, Riesemeier H, Meyer K, Goebbels J, Hellmuth, K-H (1997). Rock porosity determination by combination of X-ray computerized tomography with mercury porosimetry. Fresenius Journal of Analytical Chemistry 357:543-547.

31. Lipiec J, Hatano R (2003). Quantification of compaction effects on soil physical properties and crop growth. Geoderma 116:107-136.

32. Losano F, Marinsek G, Merlo AM, Ricci M (1999). Computed tomography in the automotive field. Development of a new engine head case study. Computerized Tomography for Industrial Applications and Image Processing in Radiology, Berlin, Germany. Proceedings BB67-CD: 65-73.

33. Luo L, Lin H, Li S (2010). Quantification of 3-D soil macropore networks in different soil types and land uses using computed tomography. Journal of Hydrology 393:53-64.

34. Mairhofer S, Zappala S, Tracy SR, Sturrock C, Bennett M Mooney SJ (2012). RooTrak: automated recovery of threedimensional plant root architecture in soil from X-ray microcomputed tomography images using visual tracking. Plant Physiology 158:561-569.

35. Mees F, Swennen R, Van Geet M, Jacobs P (2003). Applications of X-ray computed tomography in the geosciences. Geological Society, London, Special Publications 215(1):1-6.

36. Mooney S, Pridmore T, Helliwell J, Bennett M (2012). Developing X-ray computed tomography to non-invasively image 3-D root systems architecture in soil. Plant and Soil 352: 1-22.

37. Mooney SJ (2002). Three-dimensional visualization and quantification of soil macroporosity and water flow patterns using computed tomography. Soil Use and Management 18:142-151.

38. Nunan N, Ritz K, Rivers M, Feeney DS, Young IM (2006). Investigating microbial micro-habitat structure using X-ray computed tomography. Geoderma 133:398-407.

39. Orsi TH, Anderson AL (1995). X-ray computed tomography of macroscale variability in sediment physical properties, offshore Louisiana. In: Transactions of the Forty-Fifth Annual Convention of the Gulf Coast Association of Geological Societies (eds C.J. John and M.R. Byrnes), Gulf Coast Association of Geological Societies, New Orleans : 475-480.

40. Papadopoulos A, Bird NRA, Whitmore AP, Mooney SJ (2009). Investigating the effects of organic and conventional management on soil aggregate stability using X-ray computed tomography. European Journal of Soil Science 60:360-368.

41. Perret JS, Al-Belushi ME, Deadman M (2007). Nondestructive visualization and quantification of roots using computed tomography. Soil Biology and Biochemistry 39:391-399.

42. Perret J, Prasher SO, Kantzas A, Langford C (2000). A two-domain approach using CAT scanning to model solute transport in soil. Journal of Environmental Quality 29:995-1010.

43. Perret J, Prasher SO, Kantzas A, Hamilton K, Langford C (2000). Preferential solute flow in intact soil columns measured by SPECT scanning. Soil Science Society of America Journal 64:469-477.

44. Peth S, Nellesen J, Fischer G, Horn R (2010). Non-invasive 3D analysis of local soil deformation under mechanical and hydraulic stresses by mu CT and digital image correlation. Soil and Tillage Research 111:3-18.

45. Peth S, Nellesen J, Fischer G, Beckmann F, Horn R (2010). Dynamics of pore space structure investigated by X-ray microtomography.19 ${ }^{\text {th }}$ World Congress of Soil Science, Soil Solutions for a Changing World, Brisbane, Australia.

46. Peyton RL, Haeffner BA, Anderson SH, Gantzer CJ (1992). Applying X-ray CT to measure macropore diameters in undisturbed soil cores. Geoderma 53 (3-4):329-340.

47. Quinton W.L., Elliot T., Price J.S., Rezanezhad F. and Heck R., 2009 - Measuring physical and hydraulic properties of peat from X-ray tomography, Geoderma, No. 153, pp. 269-277.

48. Rogasik H, Onasch I, Brunotte J, Jegou D, Wendroth O (2003). Assessment of soil structure using X-ray computed tomography. In: Applications of X-ray Computed Tomography in the Geosciences (eds F. Mees, R. Swennen, M. Van Geet and P. Jacobs).Geological Society Special Publication, London:151-165.

49. Sander T, Gerke HH, Rogasik H (2008). Assessment of Chinese paddy-soil structure using X-ray computed tomography. Geoderma 145:303-314.

50. Schmidt S, Bengough AG, Gregory PJ, Grinev DV, Otten W (2012). Estimating root-soil contact from 3D X-ray microtomographs. European Journal of Soil Science 63:776-786.

51. Sleutel S, Cnudde V, Masschaele B, Vlassenbroek J, Dierick M, Van Hoorebeke L (2008). Comparison of different nano- and microfocus X-ray computed tomography setups for the visualization of the soil microstructure and soil organic matter. Computers and Geosciences 34:931-938.

52. Stock SR (2008). Recent advances in X-ray microtomography applied to materials. International Materials Reviews 53:129-181.

53. Sun W, Brown S, Leach R (2012). An Overview of Industrial X-ray Computed Tomography. National Physical Laboratory Report 32.

54. Taina IA, Heck RJ, Elliot TR (2008). Application of X-ray computed tomography to soil science: a literature review. Canadian Journal of Soil Science 88:1-19. 
55. Torrance JK, Elliot T, Martin R, Heck RJ (2008). X-ray computed tomography of frozen soil. Cold Regions Science and Technology 53:75-82.

56. Tracy SR, Black C, Roberts J, McNeill A, Davidson R, Tester $M$ (2012). Quantifying the effect of soil compaction on three varieties of wheat (Triticum aestivum L.) using X-ray micro computed tomography (CT). Plant and Soil 353:195-208.

57. Van Geet M, Swennen R, Wevers M (2000). Quantitative analysis of reservoir rocks by microfocus X-ray computerised tomography. Sedimentary Geology 132:2536.

58. Wang W, Kravchenko AN, Smucker AJM, Liang W, Rivers ML (2012). Intra-aggregate pore characteristics: X-ray computed microtomography analysis. Soil Science Society of America Journal 76:1159-1171.
59. Wildenschild D, Hopmans JW, Vaz CMP, Rivers ML, Rikard D, Christensen BSB (2002). Using X-ray computed tomography in hydrology: systems, resolutions, and limitations. Journal of Hydrology 267:285-297.

60. Wildenschild D, Hopmans JW, Rivers ML, Kent AJR (2005). Quantitative analysis of flow processes in a sand using synchrotron-based X-ray microtomography. Vadose Zone Journal 4:112-126.

61. Young IM, Crawford JW, Rappoldt C (2001). New methods and models for characterising structural heterogeneity of soil. Soil and Tillage Research 61:33-45.

62. Zeng Y, Gantzer CJ, Peyton RL, Anderson SH (1996). Fractal dimension and lacunarity of bulk density determined with X-ray computed tomography. Soil Science Society of America Journal 60:1718-1724. 